\title{
Rootstock influencing the quality and biogenic amines content on Syrah tropical wines
}

\author{
Rita de Cássia Mirela Resende Nassur*, Giuliano Elias Pereira², \\ Maria Beatriz Abreu Glória ${ }^{3}$, Luiz Carlos de Oliveira Lima ${ }^{4}$
}

\author{
'Bahia State University, Juazeiro, Ba- Brazil; \\ 2Embrapa Semiarid/ Grape and Wine, Petrolina, PE, Brazil \\ ${ }^{3}$ Federal University of Lavras, Lavras, MG, Brazil \\ ${ }^{4}$ Federal University of Minas Gerais, Belo Horizonte, MG, Brazill \\ *Corresponding author, e-mail: ritarnassur@hotmail.com
}

\begin{abstract}
The São Francisco Valley, in Brazil, is a region with harvest of grapes more than once a year due to the peculiar climate condition, being important to evaluate new agronomic variables for the vines and elucidade its influence on wine quality and nutritional compounds. Syrah vines grafted on different rootstocks (IAC-313 and Paulsen 1103) were cultivated in semi-arid conditions in Petrolina, PE, Brazil, and the quality of the wine was evaluated for color, sugars, acidity, phenolic compounds, antioxidant activity and the presence and contents of eight biogenic amines by HPLC (putrescine (PUT) dihydrochloride, spermidine (SPD) trihydrochloride, spermine (SPM) tetrahydrochloride, agmatine (AGM) sulfate, cadaverine (CAD) dihydrochloride, serotonine (SRT) hydrochloride, histamine (HIM) dihydrochloride, tyramine (TYM), tryptamine (TRM) and 2-phenylethylamine (PHM) dihydrochloride). For total sugars, color and antocyanins content in the evaluated wines, no effect from the rootstock was observed. For the wine produced with grapes from Syrah wines grafted on Paulsen 1103 rootstock, was observed the presence of putrescine, agmatine and phenylethylamine with the contents of 8.04, 0.15 and $0.22 \mu \mathrm{gL} \mathrm{-}^{1}$, respectively. The use of the rootstock IAC-313 on Syrah vines at the São Francisco Valley semiarid conditions, Brazil, resulted in wines with a statistical lower $\mathrm{pH}$ and soluble solid contents and higher antioxidant activity and phenolic contents, with only the presence of putrescine of the studied biogenic amines.
\end{abstract}

Keywords: antioxidant activity, phenolic compounds, semiarid, Vitis vinifera

\section{Introduction}

The São Francisco Valley, located at the Northeast of Brazil, is a region with a dry and hot climate, with temperatures that are not sufficient to induce the vine dormancy (lower than $12^{\circ} \mathrm{C}$ ), however, with the present structure and irrigation management is possible the viticulture and the production of fruits with higher quality.

Syrah (Vitis vinifera L.) is an international red cultivar, considered to be one of the noble black grape varieties due to its ability to produce dark, full-bodied, and age-worthy wines (Condurso et al., 2016) and also demonstrated a good performance on the climatic conditions of the São Francisco Valley.
The effect of grape rootstock on grape and wine composition is controversial, mainly for red grapes. Many of these tests provide conflicting information, depending on the cultivar, environmental conditions and experimental area. According to Leão et al. (2009), at the São Francisco Valley, the rootstocks that have shown satisfactory performance for table and wine grapes are hybrids such as IAC 313, IAC 572 and IAC 766. The rootstock Paulsen 1103 has shown good characteristics for table grape growing and is being tested for grape production for wine.

The concept of wine quality as being a result of local ecological factors has a great and fundamental acceptance in oenology

Accepted: 13 May 2016


(Somers et al., 2016). Thus, the particular soil and climate characteristics, the cultivar and rootstock combinations are important to wine characteristics. Understanding the mechanisms that may interfere on the phenotypic variability of a grape cultivar resulting in genotype interactions and rootstock mean a step in the study of mobile signals, expression and genetic control of favorable changes in grapevines (Albacete et al., 2015). Nevertheless, the molecular mechanisms associated with the ability of the combination of the rootstock to influence the metabolism of berries is still little elucidate (Berdeja et al., 2015).

Biogenic amines are natural contaminants formed by decarboxylation of amino acids by microorganisms (Preti \& Vinci, 2016). Several amines have been identified in wine, in contents up to $50 \mathrm{mg}$ per liter. The occurrence of biogenic amines in wines is important from a technological and toxicological point of view and can be originated from vinification techniques or even according to grape inherent compounds, climate conditions, etc (Preti \& Vinci. 2016). Biogenic amines, when in high concentrations, can cause health risk to sensitive individuals, in addition to having a negative effect on wine taste and aroma (Souza et al., 2005; Glória \& Vieira, 2007).

The aim of this study was to evaluate the influence of the rootstock used on Syrah vines on wine quality through evaluations of color, anthocyanins, total sugars, phenolic compounds, antioxidant activity and biogenic amines content.

\section{Materials and Methods}

The grape cultivar assessed was Syrah grafted on two different rootstocks: IAC-313 and Paulsen 1103 (1103-P) at the experimental area of the Bebedouro irrigation project of Embrapa Semiárido, in the municipality of Petrolina, in the state of Pernambuco, Brazil $\left(9^{\circ} 21^{\prime} \mathrm{S}, 40^{\circ} 40^{\prime} \mathrm{W}\right.$, at approximately $350 \mathrm{~m}$ of altitude). Two treatments, according to the rootstock used, performed the experiment.

The plants were installed five years before, grown on a drip-irrigated trellis system, spaced at $3.5 \times 2.0 \mathrm{~m}$. Fifteen $\mathrm{kg}$ of grapes were harvested per block in the morning at optimal maturity, based on total soluble sugars and total acidity, and were taken to the Enology Laboratory at Embrapa Semi-Arid and placed in cold chambers at $10^{\circ} \mathrm{C}$ for 12 hours, before being processed. The grapes for each block were then hand stripped and placed in an experiment container.

The wines were elaborated according to time of harvest and grape varieties using the traditional method (Peynaud e Bloin, 1997) in 200 L stainless steel vats. Alcoholic and malolactic fermentations were performed at 25 and $18^{\circ} \mathrm{C}$, respectively. The wines were then stabilized and bottled.

On the wines, the total soluble solids were determined in a filtered homogenate using a digital refractometer, model PR100 (Atago, Tokyo, Japan), with automatic temperature compensation to $25^{\circ} \mathrm{C}$. Total sugar determinations, which provide the percentage of glucose, were extracted with $70 \%$ of ethanol and determined by the Antrona method (Dische, 1962).

Wine color was measured using a colorimeter, model CR400 (Konica Minolta Business Solutions U.S.A., Ramsey, NY, USA), with an $8 \mathrm{~mm}$ light path aperture. The instrument was calibrated with a CR400 standard tile ( $Y=93.5$, $x=0.3114, y=0.3190$ ) (Konica Minolta Business Solutions U.S.A., Ramsey, NY, USA). The wine color results were characterized by: lightness ( $\left.L^{*}\right)$, which ranges from black (0) to white (100); and chromaticity $\left(C^{*}\right)$, which represents color purity. Wine $\mathrm{pH}$ was determined with a $\mathrm{pH}$ meter, model Tec3MP (Tecnal, Piracicaba, SP, Brazil). Analysis of total anthocyanins was performed following the method of differential $\mathrm{pH}$ (Giusti \& Wrolstad, 2001). A solution with acidified methanol was centrifuged at $2,000 \mathrm{~g}$ for $15 \mathrm{~min}$, at $4^{\circ} \mathrm{C}$, for sample preparation. An aliquot of the supernatant was diluted with buffers of $\mathrm{pH} 1.0$ and 4.5, and determinations were taken at wavelengths of 510 and $700 \mathrm{~nm}$ on a Varian Cary 50 probe spectrophotometer (Varian Medical Systems, Belrose, Australia). The total content of anthocyanins was calculated as cyanidin3glucoside. The total acidity was expressed in tartaric acid (\%) according to the titulation of the wine until it reached the $\mathrm{pH}$ of 8.2, 
when all the acid were neutralized by the $\mathrm{NaOH}$.

Phenolic content was determined according to the methodology of Singleton \& Rossi Junior (1965) using the FolinCiocalteu reagent. The extraction procedure involved steps of centrifugation, filtration, and rest in order to obtain a better extraction of phenolic compounds. Phenolic content was then determined by a spectrophotometer Varian Cary 50 probe (Varian Medical Systems, Belrose, Australia) at $750 \mathrm{~nm}$, and the absorption values were compared with the standard curve with gallic acid.

The determination of the antioxidant activity was realized by the DPPH method using the Rufino et al. (2007) methodology, based on the DPPH radical scavenging (2,2-Diphenyl-1picrylhidrazil) by the antioxidants compounds, leading to a decrease of absorbance at $515 \mathrm{~nm}$, with results expressed in free-radical scavenging percentage (\%FSR).

Eight biogenic amines were investigated on wines, according to standards of putrescine (PUT) dihydrochloride, spermidine (SPD) trihydrochloride, spermine (SPM) tetrahydrochloride, agmatine (AGM) sulfate, cadaverine (CAD) dihydrochloride, serotonine (SRT) hydrochloride, histamine (HIM) dihydrochloride, tyramine (TYM), tryptamine (TRM) and 2-phenylethylamine (PHM) dihydrochloride purchased from Sigma Chemical Co. (St. Louis, $M O, E U A)$. The mobile phases were filtered in HAWP and HVWP membranes, used respectively for aqueous and organic solvents $147 \mathrm{~mm}$ diameter and $0.45 \mu \mathrm{m}$ pore size, Millipore Corp., Milford, MA, USA). The amines were separated by ion pair reverse phase HPLC and quantified fluorimetrically after post-column derivatization with o-phthalaldehyde. Liquid chromatography was performed on a LC- 10AD system connected to a RF-551 spectrofluorimetric detector at 340 and $445 \mathrm{~nm}$ of excitation and emission, respectively, and to a CBM-10AD controller (Shimadzu, Kyoto, Japan) (Souza et al., 2005). A reversed-phase $\mu$ Bondapak C18 column, $300 \times$ $3.9 \mathrm{~mm}$ i.d., $10 \mu \mathrm{m}$, was used with a $\mu$ Bondapak C18 guard-pak insert (Waters, Milford, MA). The mobile phases were: $\mathrm{A}$, solution of $0.2 \mathrm{M}$ sodium acetate and $10 \mathrm{mM}$ 1-octanesulfonic acid sodium salt adjusted to $\mathrm{pH} 5.0$ with acetic acid; and $\mathrm{B}$, acetonitrile. The flow rate was set at 0.8 $\mathrm{mL} / \mathrm{min}$ and the gradient was: 13 min at $11 \% \mathrm{~B}$, 19 min at $30 \%$ B, 24 min at $11 \%$ B, and 45 min at $11 \%$ B. The post-column derivatization reagent was delivered at $0.4 \mathrm{~mL} / \mathrm{min}$. It consisted of 1.5 $\mathrm{mL}$ Brij-35, $1.5 \mathrm{~mL}$ mercaptoethanol and $0.2 \mathrm{~g}$ ophthalaldehyde dissolved in $500 \mathrm{~mL}$ solution of $25 \mathrm{~g}$ boric acid and $22 \mathrm{~g} \mathrm{KOH}$ ( $\mathrm{pH}$ adjusted to 10.5 with $3 \% \mathrm{KOH}$ ). The column and the post-column reaction apparatus were at room temperature $\left(22 \pm 1^{\circ} \mathrm{C}\right)$. The identification of amines was performed by comparison of retention time of amines in samples to standard solutions and also by addition of the suspected amine to the sample. Amine levels were calculated by direct interpolation in the standard curve.

The study of wines quality and chemical characteristics was carried out in a completely randomized design, with two treatments and four replicates, each. Means were compared by Tukey's test, at $5 \%$ of probability, except for biogenic amines, in which the values obtained by HPLC were compared to the standard peak.

\section{Results and Discussion}

On Table 1 is possible to observe the quality parameters evaluated on Syrah red wines using different rootstocks. The total soluble solids are an indirect measurement of the sugar content of the sample and the values were statistically different for wines from vines with different rootstocks. On the other hand, the total sugars did not varied statistically according to the wine evaluated, indicating that part of the soluble solids responsible for a significant difference in this parameter are not only related to sugars.

It is possible to observe a higher soluble solids content in wines from Syrah vines with the use of the Paulsen 1103 (1103-P) rootstock. In wines, the sugar content are important for a commercial classification of the wine, as it occurs in Brazil according to legislation stablished by the Brazilian Ministry of Agriculture, for example. If the wine or must have higher sugar content, less sugar will be added at the chaptalization to favoring the fermentation and resulting in a flavor more characteristic of the used grape. Vigorous rootstocks can lead to a higher sugar synthesis in the plant. 
Table 1. Soluble solids (SS), total sugar (TS), lightness (L), chromaticity (C), antocyanins (AC), pH, acidity (A), phenolics (P), antioxidant activity (AA) of Brazilian tropical 'Syrah' red wines, according to the rootstock used.

\begin{tabular}{llllllllll}
\hline Wine & SS & TS & $L^{*}$ & C & AC & pH & A & P & AA \\
\hline Syrah-313 & $9.70 \mathrm{~b}$ & $1.23 \mathrm{a}$ & $11.44 \mathrm{a}$ & $22.33 \mathrm{a}$ & $107.46 \mathrm{a}$ & $3.70 \mathrm{~b}$ & $0.69 \mathrm{a}$ & $1.63 \mathrm{a}$ & $50.19 \mathrm{a}$ \\
Syrah-1103 & $10.4 \mathrm{a}$ & $1.29 \mathrm{a}$ & $10.71 \mathrm{a}$ & $16.92 \mathrm{a}$ & $98.65 \mathrm{a}$ & $4.00 \mathrm{a}$ & $0.54 \mathrm{~b}$ & $1.15 \mathrm{~b}$ & $42.51 \mathrm{~b}$ \\
\hline
\end{tabular}

For wine color analysis, according to the variables that indicate sample lightness $\left(\mathrm{L}^{*}\right)$ and chromaticity, responsible for indicating the intensity of the coloration of the product assessed and which is a result of a calculation according to $a^{*}$ and $b^{*}$ color values obtained for wines, no statistical difference was observed (Table 1), although is it possible to observe a tendency of increase on chromaticity values for wines from Syrah vines with the IAC-313 rootstock. The color in wine is a result of the presence of monomeric anthocyanins, explaining the fact that the same wine cited above resulted in anthocyanin content about $9 \%$ higher than from wines from vines which used the Paulsen 1103 rootstock, although the difference was not considered significant. It can be observed that in Syrah vines grown in the São Francisco Valley, Brazil, little interference in berry color is due to the rootstock that was used in the cultivation of vines.

Suriano et al. (2016) Evaluating wines from Italy, affirmed that the genotype/rootstock can interact with chemical characteristics of some grape varieties, being the choice of the rootstock the decision of major importance winemaking technologies results. The same authors observed an influence on the genotypes and rootstocks on the wine anthocyanins content. This difference was not observed in the present study, probably due to the use of the same genotype, with changes only on the rootstock.

A higher acidity (Table 1) can be observed for the wine produced with Syrah grafted on the IAC-313 rootstock. The acid content in wine is a sum of the acids presented in musts with other acids produced during and after the alcoholic fermentation. The acidic compounds play an important role in keeping the wine microbiologically and chemically stable. In addition, they have a large effect on the color, taste and stability of the final product (Vidigal et al., 2016). Some studies also related the role of the rootstock on grape $\mathrm{pH}$ (Kodur et al., 2013; Jogaiah et al., 2015). The changes on plant physiology that could interfere on secondary metabolism composition leading to a higher phenolic composition of the wines should be better investigated. Nassur et al. (2014) observed that the grape cultivar can influence the chemical chemical characteristics of grape juices, regardless of the rootstock used.

The moderate consumption of wine, especially red wine, has been associated with health benefits, such as the decreasing the risk of cardiovascular diseases (Lamuela-Raventós \& Estruch, 2016). This property is due to the antioxidant effect of some wine constituents. Thus, if it is possible to find some alternatives to increase the antioxidant potential of the beverage, this management would be highly recommended. According to the results on Table 1, the use of the rootstock IAC-313 was responsible for the increase in the antioxidant activity, when evaluated by the DPPH method and also for the higher phenolic content observed in the tropical Syrah red wines.

Some studies evaluated the rootstock influence on vines phenolic compounds and the positive influence of the wine phenolic composition on wine commercial price (Granato et al., 2012), aroma composition (San Juan et al., 2012) and antioxidant properties (Llobodanin et al., 2014) has been reported.

On table 2 is possible to observe the biogenic amines incidence on Syrah tropical red wines according to the rootstock used.

Table 2. Biogenic amines ( $\mu \mathrm{g} \mathrm{mL} \mathrm{-}^{-}$) in Brazilian tropical 'Syrah' wines according to rootstock.

\begin{tabular}{lcccccccc}
\hline Wine & PUT & CAD & HIM & TYM & SRT & AGM & SPD & PEM \\
\hline Syrah-313 & 8.39 & 0 & 0 & 0 & 0 & 0 & 0 & 0 \\
Syrah-1 103 & 8.04 & 0 & 0 & 0 & 0 & 0.15 & 0 & 0.22 \\
\hline \multicolumn{2}{l}{ Putrescine (PUT), cadaverine (CAD), histamine (HIM), tyramine (TYM), serotonin (SRT), agmatine (AGM), spermidine (SPD) and phenylethylamine (PEM). }
\end{tabular}


The eight studied amines were putrescine (PUT), cadaverine (CAD), histamine (HIM), tyramine (TYM), serotonin (SRT), agmatine (AGM), spermidine (SPD) and phenylethylamine (PEM). It is possible to observe that when the rootstock IAC-313 was used, only putrescine was detected in the wines. On the other hand, the change on the rootstock for the 1103-Paulsen lead to the observation of three biogenic amines: PUT, AGM and PEM.

Biogenic amines are naturally present in wine and it is very difficult to obtain a wine that does not contain any biogenic amines (PozoBayón et al., 2012)

The occurrence of biogenic amines in wines can originate from winemaking techniques and from grape characteristics. The incidence can be a result of the contact of the must with the grape skin, aging, aminoacid profile, wine contact to the yeats, etc (Preti e Vinci, 2016).

Some people can be intolerant to histamine and normally also intolerant to wine (Konakovsky et al., 2011). Thus, is also important the attention of this consumers regarding to possible reactions of histamine-intolerant, considering foods that can contain amines.

It is important to observe that some oenological practices used to enhance wine flavor and aroma can also increase the concentration of the precursor amino acids of the biogenic amines, such as the ageing of wines and the maceration time (Preti e Vinci, 2016). Also, the type of container employed during malolactic fermentation (stainless steel or oak barrel) seems to affect the biogenic amine content of wines, suggesting that the components of wood, mainly phenolic compounds, may influence the production of biogenic amines by lactic acid bacteria (Jimenez-Moreno et al., 2003).

In the present study it is possible to observe that not only filed practices or conditions and some oenological techniques, but also the rootstock used on Syrah vines can be responsible for the biogenic amines content and the profile of the amines presented in this type of wine produced in a tropical semi-arid condition.

Furthermore, another important parameter for the occurrence of these natural contaminants is $\mathrm{pH}$, which was significantly correlated with putrescine, cadaverine and tyramine. Martin-Alvarez et al., 2006 correlated the formation of BA with high values of $\mathrm{pH}$ in wine. In the present study, it is possible to observe that the wines with a lower $\mathrm{pH}$ presented only one type of biogenic amines, between the investigated ones.

A pH under 3.3 may cause difficult malolactic fermentation, but a high $\mathrm{pH}$ can increase the susceptibility of the wine to microbial spoilage. Some authors have established a critical pH level, above which it is more difficult to control the microorganism population, with the possibility of problems arising due to the production of biogenic amines (Preti et al., 2016).

A higher antioxidant activity and phenolic compounds content were observed for the wine in which only the presence of putrescine was identified. However, a positive correlation with oenological practices and biogenic amines content was observed by Preti et al., (2016), that concluded that according to winemaking techniques, it is possible to observe higher antioxidant properties and the natural formation of amines such as putrescine and cadaverine as a drawback. These two amines have no documented adverse health effects, but can be an important issue for sensitive consumers because they can have a negative synergistic effect with the more toxic histamine and tyramine present in a meal.

\section{Conclusions}

The use of the rootstock IAC-313 on Syrah vines at the São Francisco Valley semiarid conditions, Brazil, resulted in wines with a lower $\mathrm{pH}$ and soluble solid contents and higher antioxidant activity and phenolic contents, with only the presence of putrescine of the studied biogenic amines. The use of the rootstock IAC313 on Syrah vines at the São Francisco Valley semi-arid conditions, Brazil, resulted in wines with a lower $\mathrm{pH}$ and soluble solid contents and higher antioxidant activity and phenolic contents, with only the presence of putrescine of the studied biogenic amines. When the rootstock 1103 was used, contents of putrescine, agmatine and phenylethylamine were detected, promoting wines with higher $\mathrm{pH}$ and soluble solids content. 


\section{References}

Albacete, A., Martinez-Andújar, C., MartínezPérez, A., Thompson, A.J., Dodd, I.C., Pérezalfocea, F. 2015. Unravelling rootstock $\times$ scion interactions to improvefood security. Journal of Experimental Botany 66 (8): 2211-2226.

Berdeja, M., Nicolas, P., Kappel, C., Wu Dai, Z., Hilbert, G., Peccoux, A., Lafontaine, M., Ollat, N., Gome, E., Delrot, S. 2015. Water limitation and rootstockgenotype interact to alter grape berry metabolism through transcriptome reprogramming. Horticulture Research 2 (15012): $1-13$

Condurso, C., Cincotta, F., Tripodi, G., Sparacio, A., Giglio, D. M. L., Sparla, S., \& Verzera, A. 2016. Effects of cluster thinning on wine quality of Syrah cultivar (Vitis vinifera L.). European Food Research and Technology 242: 1719-1726.

Dische, Z. 1962. General color reactions. In: Whistler, R.L.; Wolfram, M.L. (Ed.). Carbohydrate chemistry. New York: Academic Press 1: 477-512.

Giusti, M. M., Wrolstad, R. E. 2001. Characterization and measurement of anthocyanins by UVvisible spectroscopy. In: Wrolstad, R. E. (Ed.). Current protocols in food analytical chemistry. New York: J. Wiley.

Glória, M. B. A.; Vieira, S. M. 2007. Technological and toxicological significance of bioactive amines in grapes and wines. Food Science $1(2): 258-270$.

Granato, D., Chizuko, F., Katayama, U., Alves de Castro, I. 2012. Characterization of red wines from South America based on sensory properties and antioxidant activity. Journal of the Science of Food and Agriculture 92: 526-533.

Jimenez Moreno, N., Torrea Goni, D., Ancin Azpilicueta, C. 2003. Changes in amine concentrations during aging of red wine in oak barrels. Journal of Agricultural Food Chemistry 51: 5732-573.

Jogaiah, S., Kitture, A.R., Sharma, A.K., Sharma, J., Upadyay, A.K., Somkuwar, R.G. 2015. Regulation of fruit and wine quality parameters of 'Cabernet Sauvignon' grapevines (Vitis vinifera L.) by rootstocks in semiarid regions of India. Vitis Journal of grapevine research 54 (2): 65-72.

Juan, F.S., Cacho, J., Ferreira, V., Escudero, A. 2012. Aroma chemical composition of red wines from different price categories and its relationship to quality. Journal Agricultural and Food Chemistry 60: 5045-5056.

Kodur, S., Tisdall, J.M., Clingeleffer, P.R., Walker, R.R. 2013. Regulation of berry quality parameters in 'Shiraz' grape vines through rootstocks. Vitis -
Journal of grapevine research 52 (3): 125-128.

Konakovsky, $V_{\text {., }}$ Focke, M., HoffmannSommergruber, K., Schmid, R., Scheiner, O. 2011. Levels of histamine and other biogenic amines in high-quality red wines. Food Additives Contaminants 28 (4): 408-416.

Lamuela-Raventós, R. M., Estruch, R. 2016. Mechanism of the protective effects of wine intake on cardiovascular disease. In Wine Safety, Consumer Preference, and Human Health. Springer International Publishing 231-239.

Leão, P. C. S.(Ed.), Soares, J. M.(Ed.), Rodrigues, B. L. 2009. A vitivinicultura no semiárido brasileiro. Brasília: Embrapa Informação Tecnológica. Petrolina: Embrapa Semiárido 737p.

Llobodanin, L.G., Barrosos, L.P., Castro, I. A. 2014. Prediction of the functionality of young South American red wines based on chemical parameters. Australian Journal of Grape Wine Research 20: 15-24.

Martin-Alvarez, J.P., Marcobal, A., Polo, C., Moreno-Arribas, M.V. $2006 . \quad$ Influence of technological practices on biogenic amine contents in red wines. European Food Research and Technology 222:420-424.

Nassur, R.C.M.R., Pereira, G.E., Alves, J.A., Lima, L.C.O. 2014. Chemical characteristics of grape juices from different cultivar and rootstock combinations. Pesquisa Agropecuária Brasileira $49(7): 540-545$.

Ozden, M., Vardin, H., Simsek, M., Karaslan, M. 2010. Effects of rootstocks andirrigation levels on grape quality of Vitis vinifera L. CV. Shiraz. African Journal Biotechnology 9(25): 3801-3807.

Peynaud, E., Blouin, J. 1997. Connaissance et travail du vin. Paris Dunod. p.1-14.

Pozo-Bayón, M. A., Monagas, M., Bartolomè, B., \& Moreno-Arribas, V. 2012. Wine futures related to safety and consumer health: An integrated perspective. Critical Reviews in Food Science and Nutrition 52(1): 31-54.

Preti, R., Bernacchia, R., Vinci, G. 2016. Chemometric evaluation of biogenic amines in commercial fruit juices. European Food Research and Technology 1-9.

Rufino, M. do S.M,; Alves, R.E., Brito, E.S., Morais, S.M., Sampaio, C.G., Pérez-Jiménez, J., SauraCalixto, F.D. 2007. Metodologia científica: determinação da atividade antioxidante total em frutas pela captura do radical livre $\mathrm{DPPH}$. Fortaleza: embrapa agroindústria tropical. Embrapa Agroindústria de Alimentos. Comunicado Técnico 127, p.1-4. 
Singleton, V.L., Rossi J.A. 1965. Colorimetry of total phenolics with phosphomolybdicphosphotungstic acid reagents. American Journal of Enology and Viticulture 16:144-158.

Somers, T. C., Evans, M.E., Cellier, K.M. 2016. Red wine quality and style: diversities of composition and adverse influences from free $\mathrm{SO}_{2}$. VITISJournal of Grapevine Research 22:348-356.

Souza, S.C., Theodoro, K. H., Souza, E.R., Motta, S D., Glória, M.B.A. 2005. Bioactive amines in Brazilian wines: types, levels and correlation with physico-chemical parameters. Brazilian Archives of Biology and Technology 48(1): 53-62.

Suriano, S., Alba V., Di Gennaro D., Surian, M.S., Savino, M., Tarricone, L. 2016. Genotype/ rootstocks effect on the expression of anthocyanins and flavans in grapes and wines of Greco Nero n. (Vitis vinifera L.). Scientia Horticulturae 209: 309-315.

Vidigal S.S.M.P., Ramos, A.T.C., Rangel, A.O.S.S. 2016. Flow-based system for the determination of titratable acidity in wines. Food Analytical Methods 9: 2241-2245. 